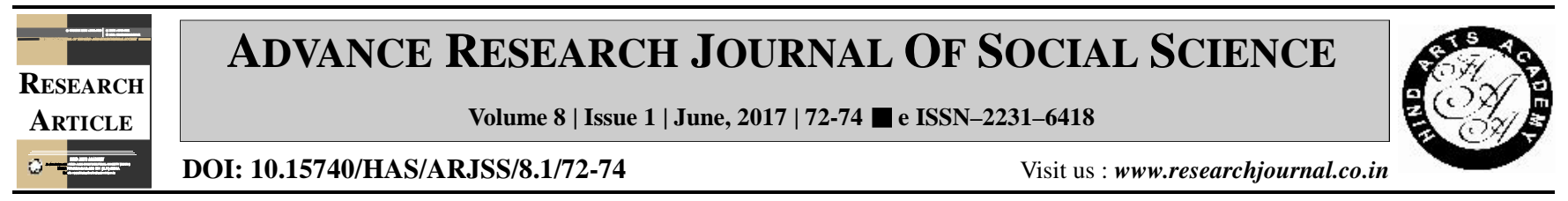

\title{
Effects of home environment in developing daily living skills in children
}

Pinki Rani*, Reetu Devi and Renu Bala

Department of Human Development and Family Studies, I.C. College of Home Science, C.C.S. Haryana Agricultural University, HISAR (HARYANA) INDIA

\section{ARTICLE INFO :}

Received

20.02.2017

Revised : 05.05 .2017

Accepted : 20.05.2017

\section{KEY WORDS :}

Home environment, Parents-child interaction, Emotional climate, Learning materials, Family companionship, Communication skill

\section{HOW TO CITE THIS ARTICLE :}

Rani, Pinki, Devi, Reetu and Bala, Renu (2017). Effects of home environment in developing daily living skills in children. Adv. Res. J. Soc. Sci., 8 (1) : 72-74, DOI: 10.15740/HAS/ARJSS/8.1/72-74.

*Author for correspondence

\begin{abstract}
Daily living skills are self-care skills such as bathing, dressing, cleaning and cooking. The present study was conducted purposively in Hisar district of Haryana state. From Hisar district two areas were selected i.e., urban and rural. The sample consist 100 girls between the age group of 7-8 years and their parents (both mother and father). 50 girls and their parents were selected randomly from Hisar city and 50 girls and their parents were selected randomly from rural area. A total of 50 boys between the age group of 7 to 8 years with both of their parents were selected randomly from each location. Hence, the total sample was 600 including (200 children and 400 their parents). Home observation for measurement of the environment (HOME) by Bradley and Caldwell (1984) and Vineland adaptive behaviour scale by Sparrow et al. (1984) used to measure the communication skill of children. Result revealed that aspect of home environment encouragement of maturity and enrichment were significantly associated with adaptive behaviour. Emotional climate, responsivity, learning material and opportunities, Family integration, family companionship, physical environment, and composite home environment were non-significantly associated with adaptive behaviour.
\end{abstract}

